Journal of medical \& pharmaceutical Sciences

Volume (5), Issue (3) : 30 Sep 2021

P: 28 - 41
AJSRP

ISSN: 2522-333X
مجلة العلوم الطبية والصيدلانية

المجلد (5)، العدد (3) : 30 سبتمبر 2021 م

ص: 28 - 41

\title{
Silver Nanoparticles AgNPs Preparation by Chemical Method to Obtain Optimal Characteristics of The Pharmaceutical Form and Study Their Effect on The Leishmania Parasite in Laboratory
}

\author{
Rama Muhamad Sattout \\ Ahmad Kamari \\ Muhamad Muayyad Bilal \\ Faculty of Science || University of Aleppo || Syria
}

\begin{abstract}
This study aimed first to prepare silver nanoparticles AgNPs in a chemical reduction, The silver nanoparticles AgNPs properties were characterized using spectroscopy of Vision and UV-Visible (UV-Vis), and atomic force microscopy (AFM) and a ZetaSizer device. This study also aimed to study the results effect of preparing Silver nanoparticles on the Leishmania parasite using an artificial environment.
\end{abstract}

The results of the spectrophotometer of the secondary silver solution with yellow color, showed maximum absorption at a wavelength of $400 \mathrm{~mm}$, while the image of atomic force microscope (AFM) showed the hierarchical morphology shape of the prepared Silver nanoparticles with an average size of $(10-30 \mathrm{~nm})$. Silver secondary particles were estimated with a diameter ranging from (12- $60 \mathrm{~nm}$ ) and with good dispersion in water by ZetaSizer device.

The results illustrated that the number of Promastigotes of the Leishmania parasite decreased after adding the Silver nanoparticles AgNPs in varying proportions, as the concentration of $500 \mu \mathrm{g} / \mathrm{ml}$ had the highest effect after 72 hours from incubation, and the percentage of remaining parasites was 5.2\% comparing with the control percentage of $14.99 \%$, while the value of IC50 was $253.075 \mu \mathrm{g} / \mathrm{ml}$, The value of R2 $=0.8809$, slope $=0.0478$ after 24 hours from incubation.

Keywords: AgNO3, AgNPs, Zetasizer, Leishmania.

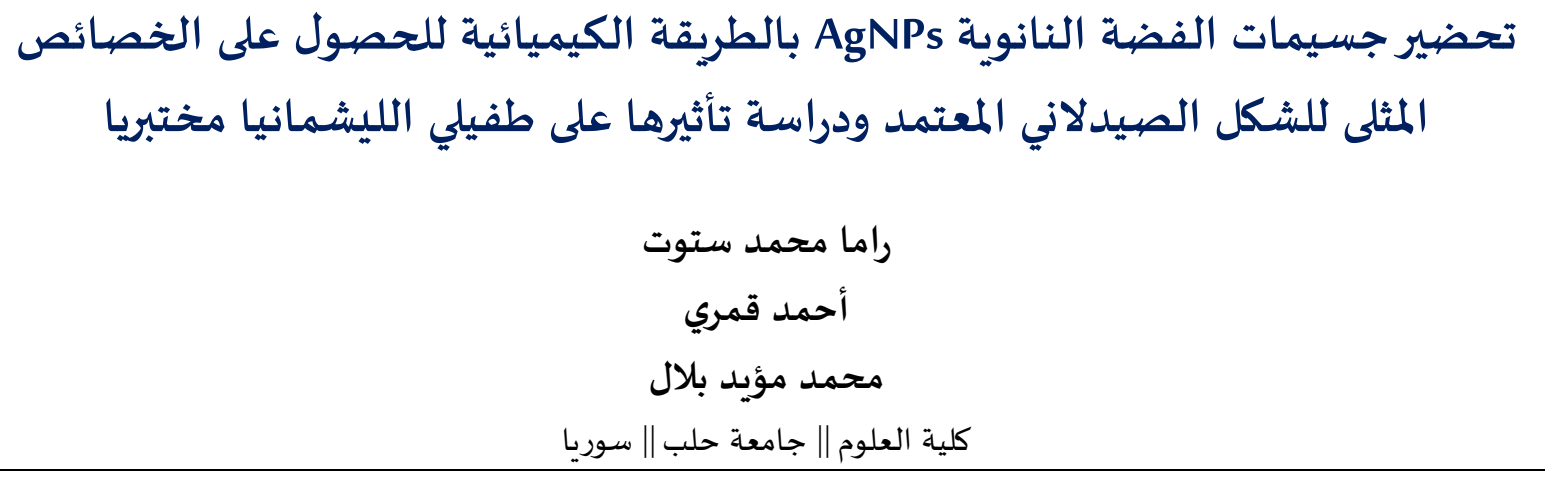

المستخلص: هدفت الدراسة إلى تحضير جسيمات الفضة النانوية AgNPs بطريقة الاختزال الكيميائي، كما تم توصيف وتحديد

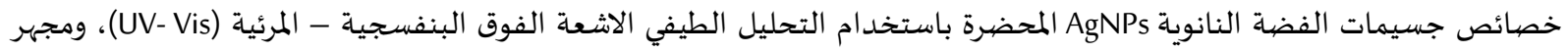

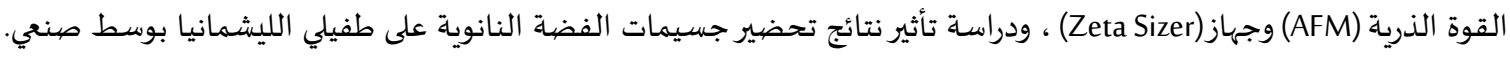
أظهرت نتائج مقياس الطيف الضوئي لمحلول الفضة النانوي ذو اللون الأصفر أقصى امتصاص عند طول موجة

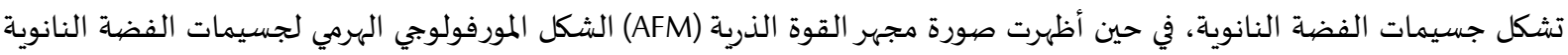




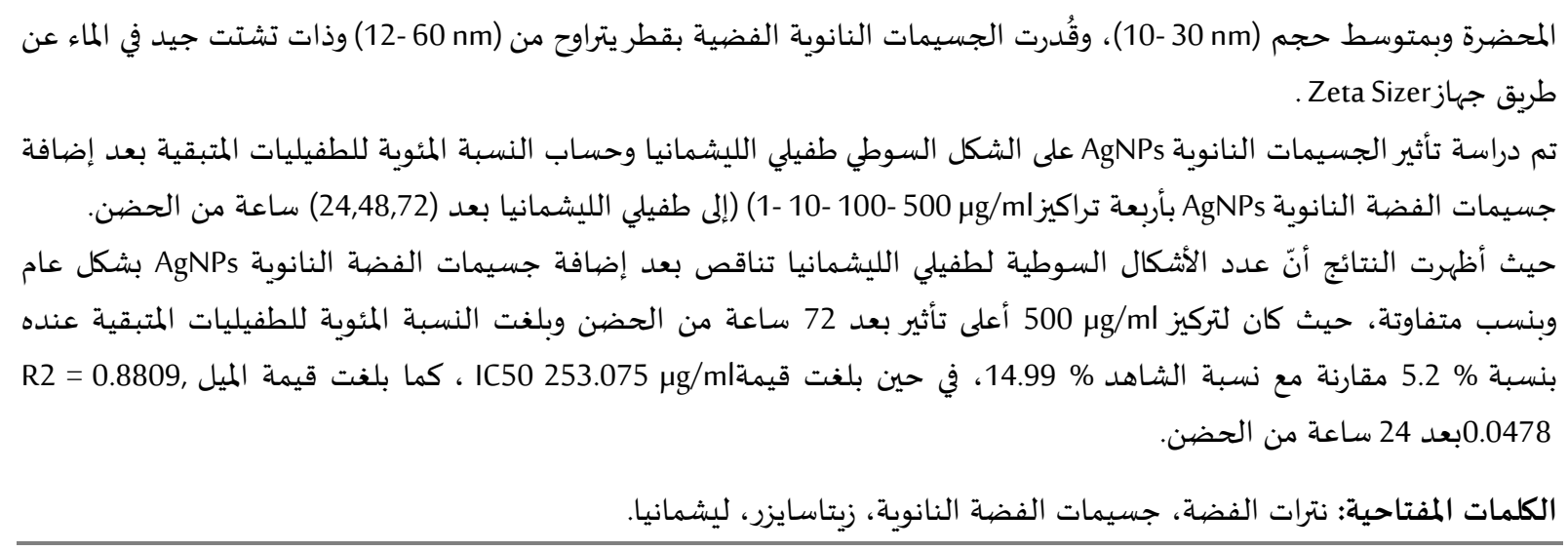

\section{1- Introduction :}

Cutaneous leishmania Disease is known by common names (Aleppo pill, eastern pill, Baghdad pill) and it is one of the most common and widespread types of leishmania, and is currently a major public health concern in developing countries. The treatment of leishmania remains a big challenge, especially in the city of Aleppo, due to the presence of many problems, including the high cost of medicines, the high number of doses, the high rate of drug resistance in addition to its side effects, and the lack of a new antileishmania treatment at reasonable prices.So far, many attempts have been made to develop low- cost drugs that have few side effects, with the aim of reaching an ideal treatment characterized by high efficacy at the lowest doses with low cost and free from harmful side effects, especially skin abnormalities, and does not require hospitalization or taking a large number of doses or the use of injections to administer the dose [1]. Because of the wide application of nanotechnology in the field of biological sciences in recent years, the creation of silver nanoparticles and their use in treating diseases was of great importance due to their distinctive physical, electrical, chemical and biological properties, so nanoparticles have great scientific importance because they have a great ability to improve human life, especially in the medical field. [2] [3]

Currently, research in the field of nanotechnology has increased due to the difference in the properties of the material at the nanoscale from its observed properties at natural size due to the difference in the surface factor to the size. [4] [5]

Recently, metal nanoparticles are the important choice due to their distinctive optical properties, catalytic, electrical, chemical and biological properties. [6]

Nanomaterials can be classified as those infinitesimal atoms, as their dimensions are within the nanometer range (1-100 nm), in this size the properties change and the particles have a large surface area and a small size that facilitate their interaction with other particles and increase their efficiency against bacteria considerably when it is compared with crystalline microscope Materials whose dimensions within the range $(1-100 \mu \mathrm{m})$. [7] 
Among the different nanoparticles, silver nanoparticles have unique properties, such as electrical conductivity and stability, and are widely used in medical fields, nanomedicine, food industries, biological studies and biomedical photography, and it has effective antibacterial and antiparasitic factor. [8] [9]

The catalytic properties of the Silver nanoparticles AgNPs also contribute to the release of silver ions from the crystal surface of the nanomaterial and their ability to remain for a long period of time, which enables them to carry out oxidation processes and ionic reactions that lead to the removal of bacteria and parasites inside cells. [7]

Due to the wide application of nanotechnology in the field ofiological sciences, the preparation of silver nanoparticles was possible, and it was done in two ways:

1. Physical method (by vaporization/condensation or laser ablation), this requires the use of a tube furnace that consumes an enormous amount of energy.

2. The chemical method that is considered one of the most desirable processes due to its simplicity, versatility of uses, and abundance of raw materials at low cost, which makes it possible to use this method to prepare nanoparticles AgNPs popular because it is characterized by saving time, cost and great effectiveness. [10]

In this method, reagents such as formaldehyde, ethylene glycol, sodium citrate, ascorbic acid and sodium borohydride are used as reducing agents, and the formation of silver nanoparticles can be observed by formation different colors according to the nanoscale size of the formed particles. [11]

\section{2- Material \& Methods:}

\section{2-1- chemicals materials:}

Silver nitrate $\left(\mathrm{AgNO}_{3}\right)$, sodium borohydride $\left(\mathrm{NaBH}_{4}\right)$, and ascorbic acid were used as reducer and fixer respectively. We also used deionized dual distillation water for the experiment procedures and characterization processes. Also were used medium of NNN, PBS, RPMI, FBS for parasite culture and multiplication as shown in Table (1)

Table (1) showing the chemicals used in the research

\begin{tabular}{|c|c|c|c|c|}
\hline Subject Name & Molecular formula & $\begin{array}{l}\text { molecular } \\
\text { weight }\end{array}$ & $\begin{array}{l}\text { the } \\
\text { manufacture } \\
\text { company }\end{array}$ & Purity \\
\hline Silver nitrate & $\mathrm{AgNO}_{3}$ & 169.873 & Mallinckrodt & $99.8 \%$ \\
\hline $\begin{array}{l}\text { sodium } \\
\text { borohydride }\end{array}$ & $\mathrm{NaBH}_{4}$ & 37.83 & HIMEDIA & $97.88 \%$ \\
\hline $\begin{array}{l}\text { Novy-MacNeal- } \\
\text { Nicolle (NNN) } \\
\text { medium }\end{array}$ & $\begin{array}{l}\text { It consists of } 0.6 \% \text { sodium chloride }(\mathrm{NaCl}) \text { added to a } \\
\text { simple blood agar slope. }\end{array}$ & - & - & - \\
\hline
\end{tabular}




\begin{tabular}{|c|c|c|c|c|}
\hline Subject Name & Molecular formula & $\begin{array}{l}\text { molecular } \\
\text { weight }\end{array}$ & $\begin{array}{c}\text { the } \\
\text { manufacture } \\
\text { company }\end{array}$ & Purity \\
\hline $\begin{array}{c}\text { Phosphate- } \\
\text { buffered saline } \\
\text { (PBS) }\end{array}$ & $\begin{array}{l}\text { It is a water- based salt solution containing disodium } \\
\text { hydrogen phosphate, sodium chloride and, in some } \\
\text { formulations, potassium chloride and potassium } \\
\text { dihydrogen phosphate }\end{array}$ & - & $\begin{array}{l}\text { Invitrogen } \\
\text { TM }\end{array}$ & - \\
\hline $\begin{array}{l}\text { RPMI- } 1640 \\
\text { medium }\end{array}$ & $\begin{array}{l}\text { One liter of RPMI } 1640 \text { contains: } \\
\text { *Glucose ( } 2 \mathrm{~g} \text { ) } \\
\text { *pH indicator (phenol red, } 5 \mathrm{mg} \text { ) } \\
\text { *Salts (6 g sodium chloride, } 2 \mathrm{~g} \text { sodium bicarbonate, } \\
1.512 \mathrm{~g} \text { disodium phosphate, } 400 \mathrm{mg} \text { potassium } \\
\text { chloride, } 100 \mathrm{mg} \text { magnesium sulfate, and } 100 \mathrm{mg} \\
\text { calcium nitrate) } \\
\text { *Amino acids (300 mg glutamine; } 200 \text { mg arginine; } 50 \\
\text { mg each asparagine, cystine, leucine, and isoleucine; } \\
40 \text { mg lysine hydrochloride; } 30 \text { mg serine; } 20 \text { mg each } \\
\text { aspartic acid, glutamic acid, hydroxyproline, proline, } \\
\text { threonine, tyrosine, and valine; } 15 \text { mg each histidine, } \\
\text { methionine, and phenylalanine; } 10 \text { mg glycine; } 5 \text { mg } \\
\text { tryptophan; and } 1 \text { mg reduced glutathione) } \\
\text { *Vitamins (35 mg i- inositol; } 3 \text { mg choline chloride; } 1 \\
\text { mg each para- aminobenzoic acid, folic acid, } \\
\text { nicotinamide, pyridoxine hydrochloride, and thiamine } \\
\text { hydrochloride; } 0.25 \text { mg calcium pantothenate; } 0.2 \text { mg } \\
\text { each biotin and riboflavin; and } 0.005 \text { mg }\end{array}$ & - & $\begin{array}{l}\text { BIOCHROM } \\
\text { AG }\end{array}$ & - \\
\hline $\begin{array}{l}\text { Fetal bovine } \\
\text { serum (FBS) }\end{array}$ & $\begin{array}{l}\text { contains more growth factors and has lower gamma } \\
\text { globulin (i.e., antibodies) content and non- fetal serum }\end{array}$ & - & GIBCO & - \\
\hline
\end{tabular}

\section{2- 2- Preparation of Silver nanoparticles AgNPs:}

Silver nanoparticles (AgNPs) were prepared by chemical reaction by reduction sodium borohydride $\left(\mathrm{NaBH}_{4}\right)$ to silver nitrate $\left(\mathrm{AgNO}_{3}\right)$ and ascorbic acid as a fixer through the following steps:

adding $100 \mathrm{ml}$ of $\mathrm{AgNO}_{3}$ solution at a concentration of $\left(1 * 10^{-3} \mathrm{M}\right)$, then the solution stirred vigorously using a magnetic mixer at $70 \mathrm{C}^{\circ}$ to ensure homogeneity of the mixture. While the solution was steady at a temperature of $70 \mathrm{C}^{\circ}, 5 \mathrm{ml}$ of $\mathrm{NaBH}_{4}\left(2 * 10^{-3} \mathrm{M}\right)$ was gradually added to the solution, then the solution was cooled to room temperature and the products were kept in glass tubes after centrifugation it at $4 \mathrm{C}^{\circ}$. 


\section{2- 3- Preparing of nanoscale films for AgNPs:}

Preparing a thin film on glass slides containing silver nanoparticles by chemical deposition, where the slides were dipped in a silver solution and left to dry at room temperature. as shown in Table (2)

Table (2) Table of laboratory equipment used in research

\section{Device name Basic hardware specifications}

UV- VIS spectrometer from SCINCO Company- No. S- 3100, in which the absorption spectrum of samples, whether films or solutions, is measured. For samples in the form of solutions,

UV cells made of quartz, glass or plastic with dimensions $(1 * 1 * 1) \mathrm{cm}$ are used. calibration of spectrophotometer the device by taking a nice Ayari solution to the incubator for the sample and then the sample placed within the cell is extended by adding the amount of the material solution so that the incubator transparent sample where the field of measurement within this spectroscope is becoming $(200-1100) \mathrm{nm}$

Atomic Force Microscope (AFM) from Cypher VRS1250 company, it is a surface scanning technique that has sub- nanometer scale resolution. AFM describes a group of techniques

Atomic Force Microscope (AFM) used for non- destructive surface studies at the nanoscale. They have a resolution on the order of 103 times better than optical microscopy's resolution limit. AFM is used widely to collect data on various mechanical, functional and electrical properties at the nanoscale as well as for topography (surface) studies.

from Malvern Panalytical's compliance, the Zetasizer offers particle size, particle charge (zeta potential) and molecular weight analysis. In addition, each benefits from advances

ZetaSizer including Adaptive Correlation, M3- PALS zeta potential analysis, constant current zeta mode and our deep learning-based data quality advice system.

Magnetic Mixer from ONiLAB 5 inch LED Digital Hotplate Magnetic Stirrer Hot Plate with Ceramic Coated Lab Hotplate, $280^{\circ} \mathrm{C}$ Stir Plate, Magnetic Mixer.

Accurate Temperature Control and Excellent Heating Capacity: Equip with internal

Magnetic Mixer temperature sensor and PT1000 external temperature probe sensor with accuracy of $0.5^{\circ} \mathrm{C}$, Automatically identifies temperature sensor PT1000 and switches to probe mode when it is plugged in. Ceramic coated stainless steel hotplate with good chemical resistance, fast heat transfer and cool- down.

Easy Use and Excellent Stirring Capacity: Maximum stirring quantity can reach up to $5 \mathrm{~L}$ and max 3L at max speed 1500rpm.

\section{2- 4- Characterization of AgNPs:}

UV- visible spectroscopy is One of the most widely used techniques for characterizing nanoparticles, it was observed at room temperature using a dual UV spectrophotometer with wave length (200- $1100 \mathrm{~nm})$, using distilled deionized water as a solution.

The morphological properties and size of AgNPs on the films were studied using Atomic Force Microscope (AFM) technology, and samples were examined by ZetaSizer to determine the diameter and distribution of the nanoparticles in water. 


\section{2- 5- Preparation an concentrations series of AgNPs:}

A series of dilute solutions were prepared by adding silver nanoparticles AgNPs to dual distillation water to obtain the following concentrations: (1-10-100-500 $\mu \mathrm{g} / \mathrm{ml}$ ), immediately before use.

\section{2- 6- Isolating and culturing Leishmania parasite samples:}

Isolated parasites samples were taken weekly from patients who were positive for the disease, and samples were cultured immediately after they were taken from the lesion by placing them directly into one of the tubes contained NNN medium and mixing them with drops of saline solution PBS which added prior to culturing.

Samples were cultured near a Benzene lamp and the parasite culture media were incubated at 26 $\mathrm{C}^{\circ}$

The tubes were examined daily to oversee the changing of parasites in terms of shape, movement and number. Besides that, The media were regenerated and the parasite multiplied using RPMI- 1640 medium and Fetal bovine serum FBS.

\section{2- 7- Effecting of AgNPs on the Promastigote shape of Leishmania parasite:}

The Promastigote forms that taken from culturing medium (RPMI with adding of 15\% FBS) were added at a density of $2 \times 10^{6}$ cells $/ \mathrm{ml}$ at the following concentrations: (1- 10- 100- $500 \mu \mathrm{g} / \mathrm{ml}$ ) of silver nanoparticles AgNPs in a plate containing 96 Chamber in the form of three replicates and incubated at 24 $\mathrm{C}^{\circ}$.

Besides that, the flag Promastigote shapes were cultured as three replicates without AgNPs as the control group.

\section{2-8- Calculating the number of remaining parasites and the Half- Maximal Inhibitory Concentration $\left(\mathrm{IC}_{50}\right)$ :}

The status and number of Promastigote shape were determined by cell counting with an enhanced Neubauer Chamber before addition AgNPs and after 24, 48 and 72 hours from incubation.

The Half- Maximal Inhibitory Concentration $\left(\mathrm{IC}_{50}\right)$ was calculated, which is the most commonly used standard to determine the effectiveness of a treatment to inactivate the parasite by half.

The percentage of remaining parasites after adding AgNPs was calculated by means of the EXCEL program.

\section{2-9-Statistical Studying:}

The statistical analysis was performed using Spss program, where the One- Way Analysis Of Variance (ANOVA) test coefficient was used to find a significant difference at a significance level of 0.05 
between the results, and the Least Significant Difference (LSD) function was also applied to determine the results that between it there is a significant difference.

\section{3- Results:}

\section{3- 1- Results of preparing silver nanoparticles of AgNPs:}

The results of preparing AgNPs showed that the yellow color solution gradually changed with the passage of time to a reddish brown color. The transformation of the transparent silver nitrate solution to yellow after the addition of the sodium borohydride solution is considered an indication of the form of $\mathrm{Ag}^{0}$ according to the following reaction:

$$
\mathrm{AgNO}_{3}+\mathrm{NaBH}_{4} \rightarrow \mathrm{Ag}^{0}++\mathrm{H}_{2}+\mathrm{B}_{2} \mathrm{H}_{6}+\mathrm{NaNO}_{3}
$$

Note that the reaction was carried out in a dark atmosphere to avoid unnecessary photochemical reactions

\section{3- 2- Results of characterization of AgNPs:}

\section{3- 2-1- UV- Vis spectroscopy:}

Measuring the absorption spectrum of the silver nanoparticles AgNPs sample within the range (200-1100 nm), where the nanoparticles were suspended in distilled water, and through it an absorption peak was observed at $400 \mathrm{~nm}$, which indicates the formation of silver nanoparticles as in Figure (1).

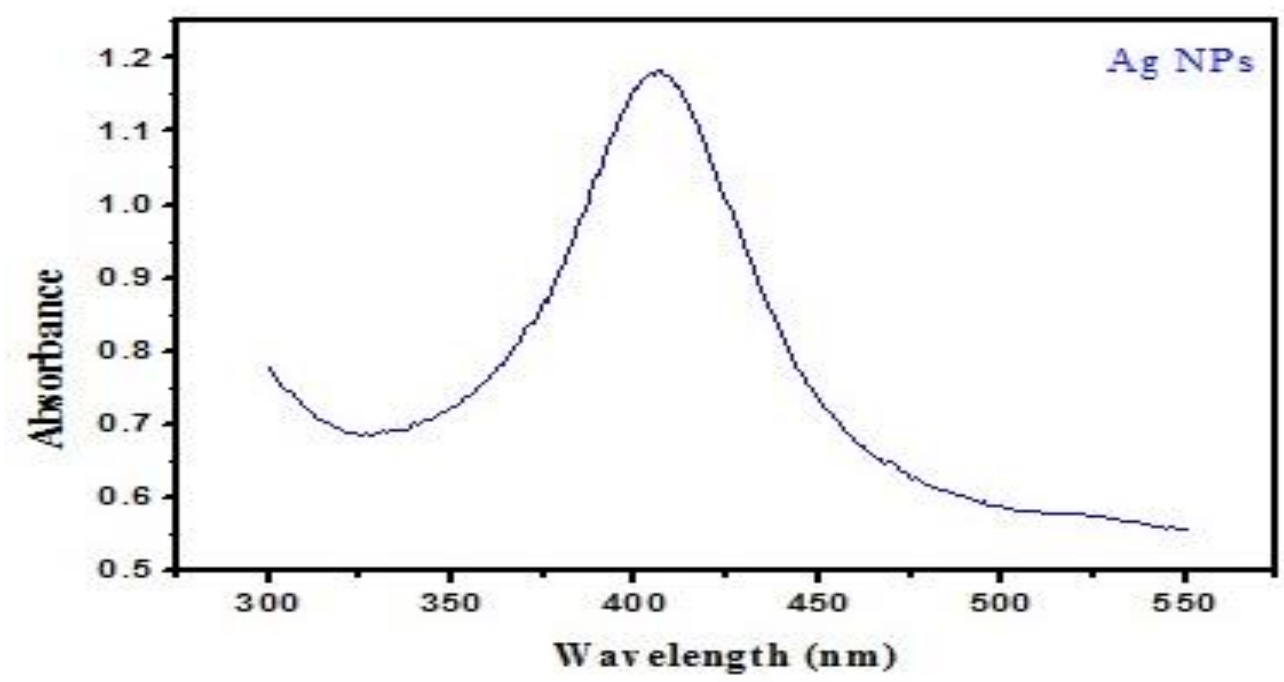

Figure (1): UV- Vis absorption spectrum of AgNPs solution.

\section{3- 2- 2- Examination by atomic force microscopy (AFM):}

It is a type of nanometer resolution microscopy used to create a three-dimensional image of the sample surface with high accuracy and this is achieved by point- scanning the sample position to display the surface topography and the shape of the silver nanoparticles AgNPs. 
The AFM image was performed to oversee the size and formation of the prepared silver nanoparticles to verify the elongated hierarchy of AgNPs, where the 3D image of the film in a $2 \mathrm{~mm}$ scanning. Whereas, the nanofilm of silver was $10 \mathrm{~nm}$ in deep with a homogeneous shape of the nanoparticles as in Figure (2:a).

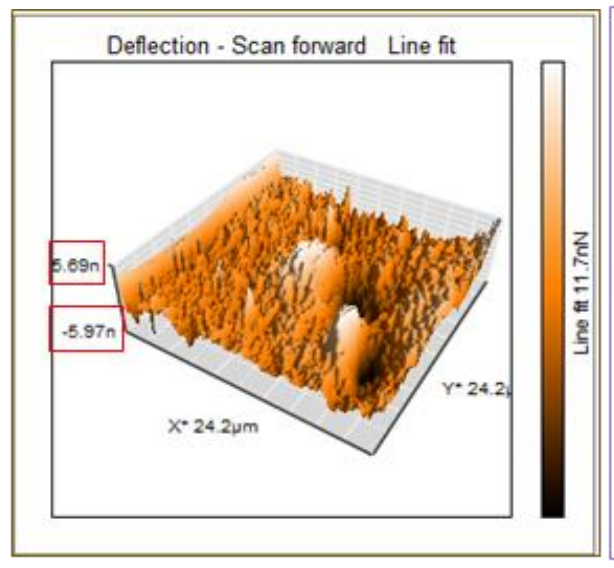

(a)

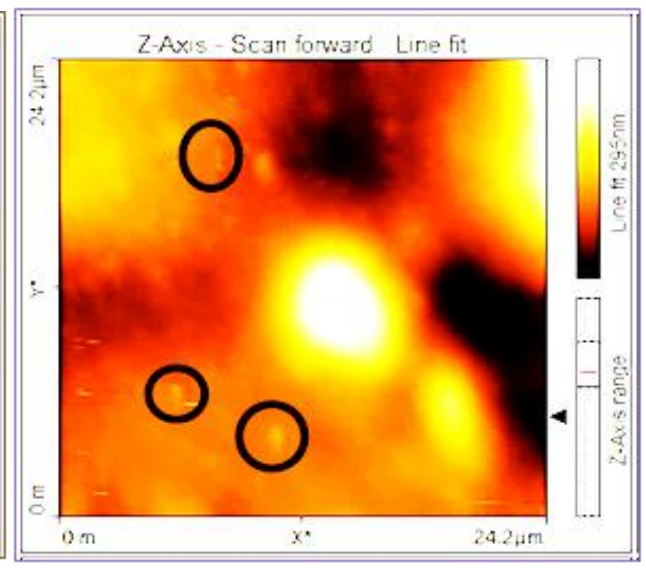

(b)

Figure (2): image of silver nanoparticles using an AFM microscope (a): 3D image, (b): shap particles

While the film image of the nanoscale membrane which prepared on the glass slide using AFM microscopy showed a clear shape to forming the particles. All of them were elongated pyramids with the shape of a sesame seed with an average diameter equal to $(10-30 \mathrm{~nm})$, as shown in Figure (2:b).

\section{3- 2- 3- Distribution and grain homogeneity using ZetaSizer technology:}

ZetaSizer measurements are important when preparing nanomaterials, which they are used to study the size distribution of nanoparticles, their uniformity of distribution, stability and propensity to aggregate, which gives an idea about the surface area of the prepared particles.

In this study, AgNPs were suspended in dual distillation water within the chamber and their dimensions were measured. Our results showed agreement with the reference studies ${ }^{[12][9]}$ and found that the size of the silver nanoparticles with a diameter within the range (12- $60 \mathrm{~nm})$, which has a good homogeneous distribution and dispersion in water as shown in Figure (3).

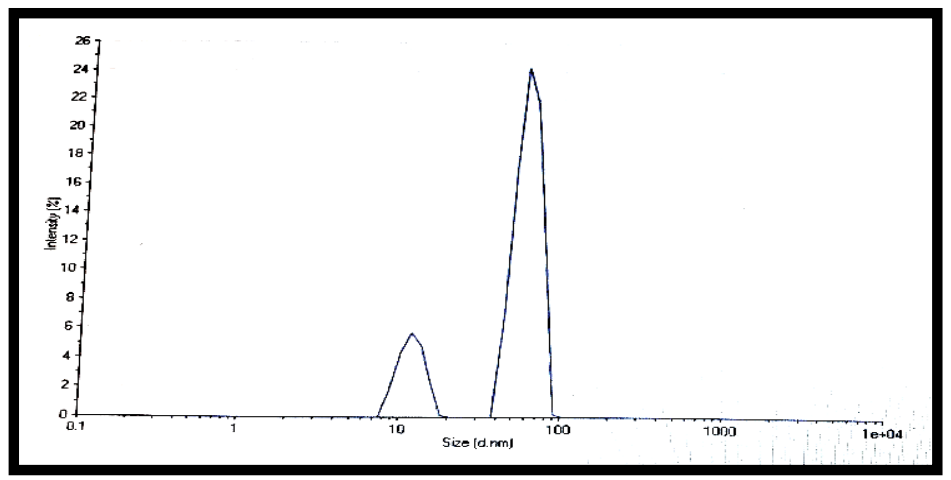

Figure (3) ZetaSizer diagram for silver nanoparticles size 


\section{3- 2- 4- The effect of AgNPs on the Promastigote of the Leishmania parasite:}

The results of the study showed that the number of Promastigote shapes of the Leishmania parasite which treated with different concentrations and times, decreased after adding the silver nanoparticles AgNPs compared to the control group.

Where at the concentration of $500 \mu \mathrm{g} / \mathrm{ml}$ of AgNPs after (72-48- 24) hours, the ratio reached the values $(5.2,7.48,14.99) \%$, respectively. Whereas, at concentration of $100 \mu \mathrm{g} / \mathrm{ml}$ after $(72-48-24)$ hours, the ratio values were $(8.35,10.66,28.32) \%$, respectively. And at concentration was $10 \mu \mathrm{g} / \mathrm{ml}$ after (2448- 72 ) hours, the ratio values were $(14.03,17.04,36.17) \%$, respectively. At $1 \mu \mathrm{g} / \mathrm{ml}$ concentration after (24- 48 - 24$)$ hours, the ratio values were $(24.45,27,83,42.94) \%$, respectively.

This is confirmed by the results of the statistical analysis using the analysis of variance test factor that there are significant differences between the used concentrations, where the probability value was $\mathrm{p}=0.0000<0.005$, and using the LSD test, we found that the concentration of $500 \mu \mathrm{g} / \mathrm{l}$ was more effective than the rest of the concentrations, where the value reached Probability $p=0.000<0.005$, and the value of $I_{50}$ was equal to 253.075 as shown in Table (3) and Figures (4) (5) (6).

Table (3) Average numbers of Promastigote for Leishmania parasite after adding silver particles AgNPs in $(24,48,72) h$.

\begin{tabular}{|c|c|c|c|c|c|c|}
\hline \multirow{3}{*}{$\begin{array}{c}\text { AgNPs } \\
\text { concentration } \\
(\mu \mathrm{g} / \mathrm{ml})\end{array}$} & \multicolumn{6}{|c|}{ Viabile Parasite number } \\
\hline & \multicolumn{2}{|c|}{24 hours } & \multicolumn{2}{|c|}{48 hours } & \multicolumn{2}{|c|}{ hours 72} \\
\hline & $\begin{array}{l}\text { Average } \\
\text { number of } \\
\text { parasites }\end{array}$ & percentage $\%$ & $\begin{array}{l}\text { Average } \\
\text { number of } \\
\text { parasites }\end{array}$ & $\begin{array}{c}\text { percentage } \\
\%\end{array}$ & $\begin{array}{l}\text { Average } \\
\text { number of } \\
\text { parasites }\end{array}$ & percentage\% \\
\hline 500 & 680000 & 14.99 & 407000 & 7.48 & 2870000 & 5.2 \\
\hline 100 & 1280000 & 28.32 & 580000 & 10.66 & 460000 & 8.35 \\
\hline 10 & 1640000 & 36.17 & 927000 & 17.04 & 7730000 & 14.03 \\
\hline 1 & 1947000 & 42.94 & 1514000 & 27.83 & 1347000 & 24.45 \\
\hline Control & \multicolumn{2}{|c|}{4534000} & \multicolumn{2}{|c|}{5440000} & \multicolumn{2}{|c|}{550700} \\
\hline The probability value $(P)$ & \multicolumn{6}{|c|}{$P=0.00<0.05$} \\
\hline LSD & \multicolumn{6}{|c|}{$P=0.00<0.05$} \\
\hline
\end{tabular}


المجلة العربية للعلوم ونشر الأبحاث ـ مجلة العلوم الطبية والصيدلانية ـ المجلد الخامس ـ العدد الثالث ـ سبتمبر 1

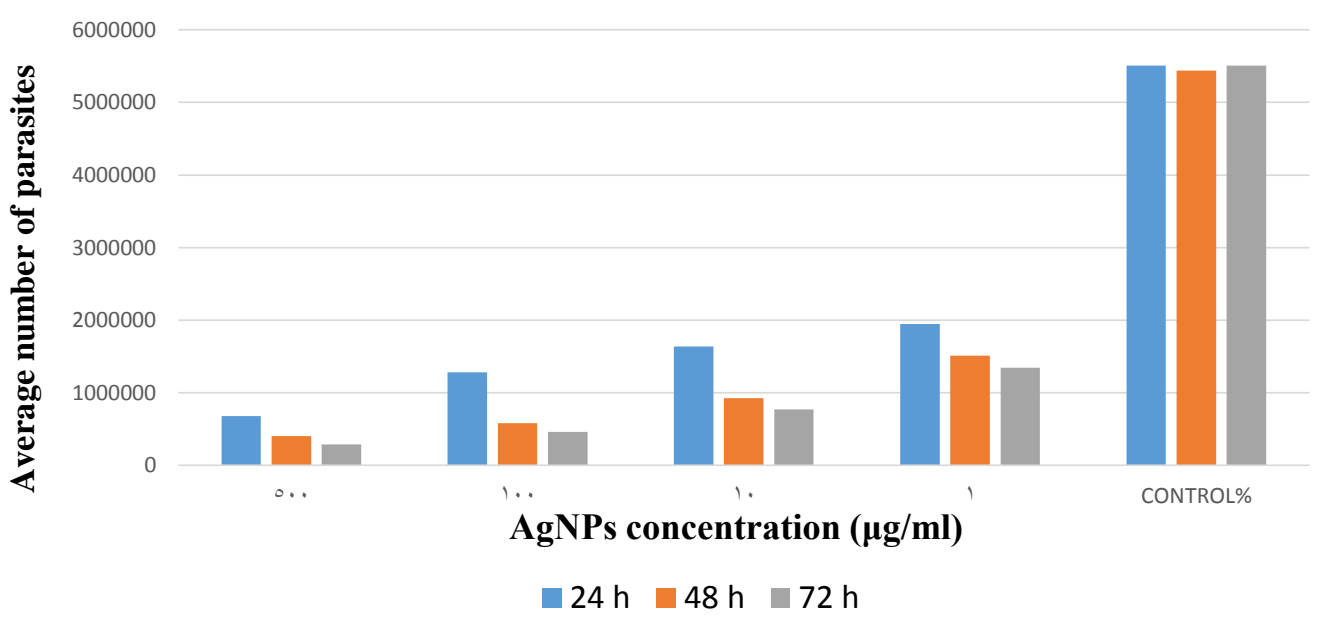

Figure (4) Chart Illustrates the average numbers of Promastigote for the Leishmania parasite after adding silver particles AgNPs in $(24,48,72) \mathrm{h}$

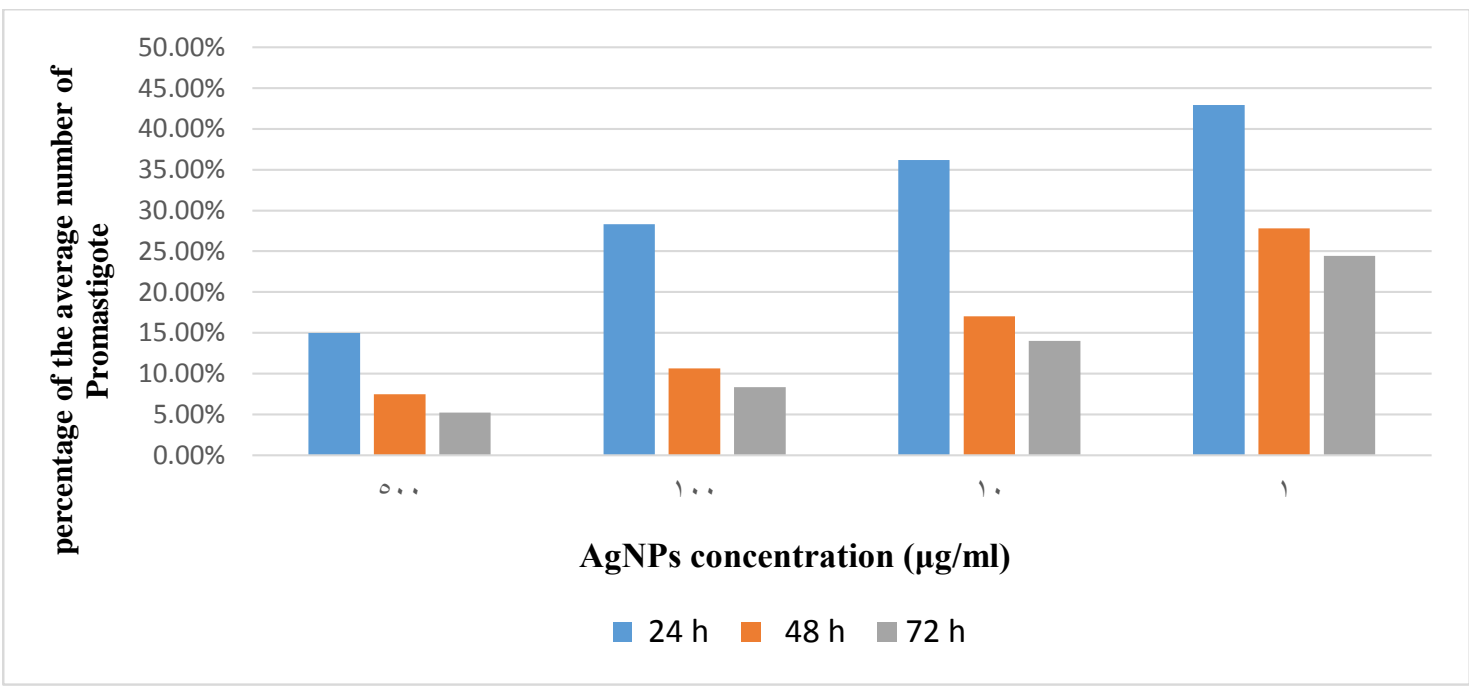

Figure (5) Chart Illustrates the percentage of the average number of Promastigote of the Leishmania parasite after adding silver particles AgNPs in $(24,48,72) \mathrm{h}$ 

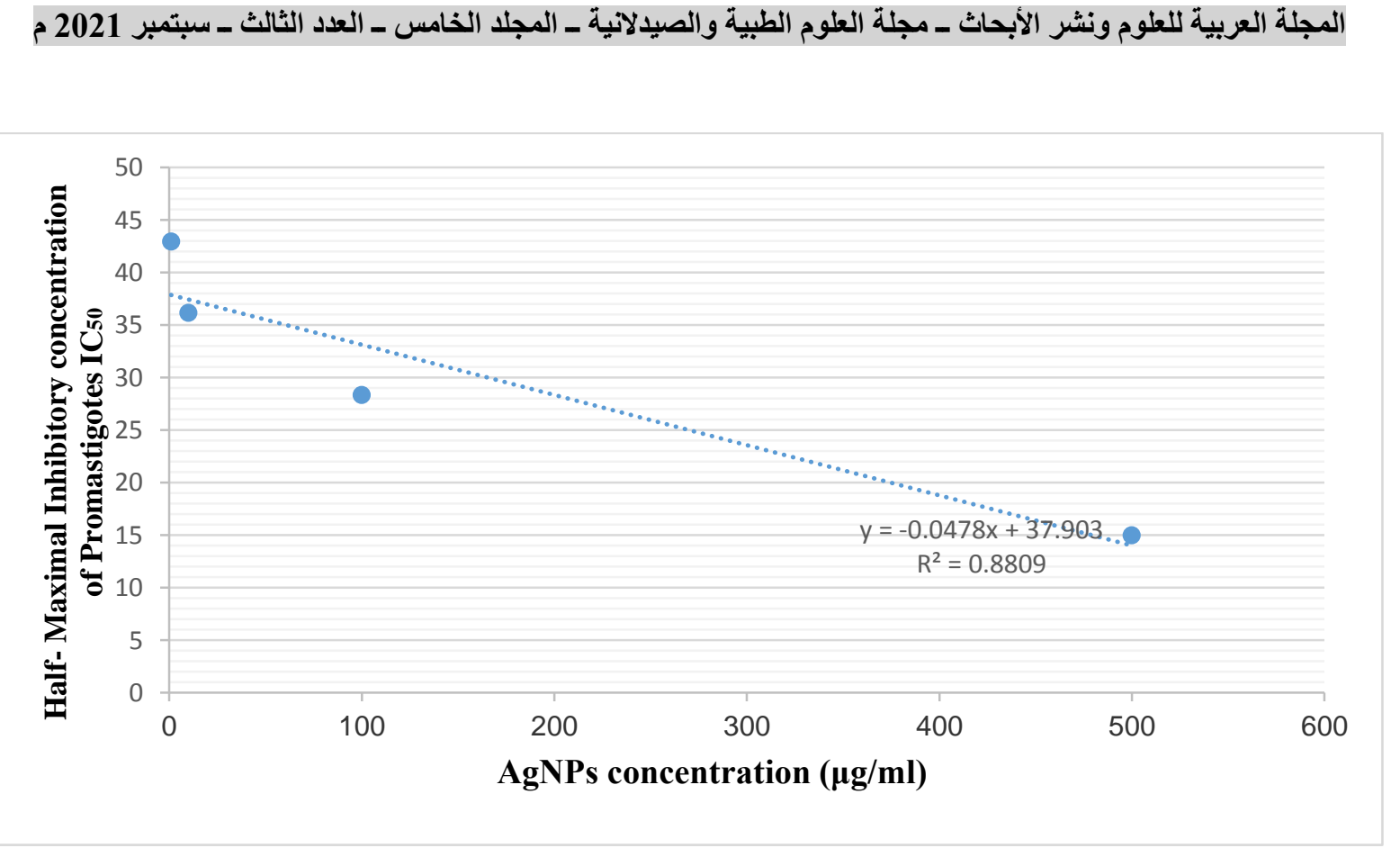

Figure (6) Chart Illustrates the Half- Maximal Inhibitory concentration of Promastigotes of the Leishmania parasite after adding silver particles AgNPs in $24 \mathrm{~h}$

\section{4- Discussion:}

The results of our research showed that the silver nanoparticles AgNPs were prepared by chemical reduction method in the form of a yellow-colored suspension, and this is Corresponds with the results of the following reference studies ${ }^{[2]}[13]$ [5].

After characterization of the silver nanoparticles was carried out using a UV Spectrophotometer Our results were corresponds with those of the reference studies ${ }^{[11][10]}{ }^{[4]}$, Which confirmed that the absorption spectrum located between (405-413nm) indicates the formation of AgNPs with small size and uniform dispersion.

Our study of the images on an Atomic Force Microscope (AFM) are also was correspons with the results of the reference studies. ${ }^{[12][6][7][9]}$

While The results in the film image of the nanoscale membrane This is in agreement with the results of the reference studies ${ }^{[13][3][14]}$ the sample images showed pyramidal particles with an average diameter of $34 \mathrm{~nm}$ and a homogeneous distribution. Other studies ${ }^{[15]}$ also showed that the greater the time of the chemical reaction, the greater the size of the nanoparticle, with the appearance of some particles with sizes up to $70 \mathrm{~nm}$.

The results of our studies also on Zetasizer showed agreement with the reference studies ${ }^{[12]}$ [9] and found that the size of the silver nanoparticles with a diameter within the range (12- $60 \mathrm{~nm})$, which has a good homogeneous distribution and dispersion in water. 
The efficiency of the silver nanoparticles AgNPs was high in inhibiting the Promastigote shape form of the Leishmania parasite. This results was in agreement with the results of the following reference studies ${ }^{[16]}[17][18]$

This was confirmed by the results of our study, as it showed the inhibitory effect of AgNPs on the Promastigote shape of Leishmania through mechanisms that include inhibition of diffusion, apoptosis, mitochondrial degradation, oxidative stress, releasing of Reactive Oxygen Species (ROS), and modifications to genetic material and degradation it.

In addition, and return to the results, we noted that the effects of the different concentrations affected the movement of the Promastigotes of the Leishmania parasite significantly, as it decreased after adding the AgNPs compared to the control group, so the movement at the concentration of $500 \mu \mathrm{g} / \mathrm{ml}$ was almost non- existent accompanied with parasite wrapping in a circular motion around itself with evanescence of its size, while the movement of the parasite increased as the concentration of silver nanoparticles decreased compared to the control group.

This was corresponds with the results of the studying ${ }^{[1]}$, which ensured the decrease the number of Promastigote accompanied with small shape and undifferentiated organelles when adding silver nanoparticles AgNPs comparing with the control group.

The studying ${ }^{[16]}$ also showed the toxic effect of AgNPs against the promastigote shape of $L$. amazonensis, where the treatment caused mitochondrial destruction and increased ROS production.

\section{5- Conclusions:}

AgNPs were obtained by chemical reduction method using sodium borohydride as a reducing agent and in the presence of a stabilizing factor of ascorbic acid.

The results of the study illustrated that the prepared AgNPs have pyramid-shape and its average diameter is $30 \mathrm{~nm}$. The laboratory studying proved the ability of using prepared silver AgNPs as antipromastigote shape of Leishmania. Prepared Silver AgNPs in this research showed high efficacy as a promastigote motion inhibitor material.

\section{6- References:}

1- Dolat, E., Rajabi, O., Salarabadi, S. S., Yadegari-Dehkordi, S., \& Sazgarnia, A, “Silver nanoparticles and electroporation: their combinational effect on Leishmania major", Bioelectromagnetics, 2015, 36(8), 586- 596.

2- Zielińska, A., Skwarek, E., Zaleska, A., Gazda, M., \& Hupka, J. “Preparation of silver nanoparticles with controlled particle size", Procedia Chemistry, 2009, 1(2), 1560- 1566. 
3- Das, S., Bandyopadhyay, K., \& Ghosh, M. M, "Effect of stabilizer concentration on the size of silver nanoparticles synthesized through chemical route", Inorganic Chemistry Communications,2021, 123, 108319.

4- Mavani, K., \& Shah, M, "Synthesis of silver nanoparticles by using sodium borohydride as a reducing agent", International Journal of Engineering Research \& Technology, 2013, 2(3), 1- 5.

5- Suriati, G., Mariatti, M., \& Azizan, A, "Synthesis of silver nanoparticles by chemical reduction method: Effect of reducing agent and surfactant concentration". International journal of automotive and mechanical engineering,2014, 10, 1920.

6- Agnihotri, S., Mukherji, S., \& Mukherji, S, "Size- controlled silver nanoparticles synthesized over the range 5-100 nm using the same protocol and their antibacterial efficacy", Rsc Advances, 2014, 4(8), 3974- 3983.

7- Raza, M. A., Kanwal, Z., Rauf, A., Sabri, A. N., Riaz, S., \& Naseem, S, "Size- and shape- dependent antibacterial studies of silver nanoparticles synthesized by wet chemical routes", Nanomaterials, $2016,6(4), 74$.

8- Gorup, L. F., Longo, E., Leite, E. R., \& Camargo, E. R, “Moderating effect of ammonia on particle growth and stability of quasi- monodisperse silver nanoparticles synthesized by the Turkevich method". Journal of colloid and interface science, 2011, 360(2), 355- 358.

9- Iravani, S., Korbekandi, H., Mirmohammadi, S. V., \& Zolfaghari, B, "Synthesis of silver nanoparticles: chemical, physical and biological methods", Research in pharmaceutical sciences,2014, 9(6), 385.

10- Fanti, J. R., Tomiotto- Pellissier, F., Miranda- Sapla, M. M., Cataneo, A. H. D., de Jesus Andrade, C. G. T., Panis, C., \& Conchon- Costa, I, “Biogenic silver nanoparticles inducing Leishmania amazonensis promastigote and amastigote death in vitro", Acta tropica, 2018, 178, 46- 54.

11- Karthikeyan, B., Govindhan, R., \& Amutheesan, M, “Chemical Methods for Synthesis of Hybrid Nanoparticles", In Noble Metal- Metal Oxide Hybrid Nanoparticles, 2019, (pp. 179- 188).

12- Mohammed, O. T., Abdulkhaliq, R. J., \& Mohammed, S. T, “The effects of Fusarium graminarum silver nanoparticles on leishmania tropica", In Journal of Physics: Conference Series, 2019, (Vol. 1294, No. 6, p. 062075).

13- Kumar, S. V., Bafana, A. P., Pawar, P., Rahman, A., Dahoumane, S. A., \& Jeffryes, C. S, “High conversion synthesis of $<10 \mathrm{~nm}$ starch- stabilized silver nanoparticles using microwave technology", Scientific reports, 2018,8(1), 1- 10.

14- Vu, X. H., Duong, T. T. T., Pham, T. T. H., Trinh, D. K., Nguyen, X. H., \& Dang, V. S. "Synthesis and study of silver nanoparticles for antibacterial activity against Escherichia coli and Staphylococcus aureus". Advances in Natural Sciences: Nanoscience and Nanotechnology, 2018, 9(2), 025019. 
15- Qin, Y., Ji, X., Jing, J., Liu, H., Wu, H., \& Yang, W, “Size control over spherical silver nanoparticles by ascorbic acid reduction",Colloids and Surfaces A: Physicochemical and Engineering Aspects, 2010, 372(1-3), 172- 176.

16- Rossi- Bergmann, B., Pacienza- Lima, W., Marcato, P. D., De Conti, R., \& Durán, N, “Therapeutic potential of biogenic silver nanoparticles in murine cutaneous leishmaniasis", In Journal of Nano Research, 2012, (Vol. 20, pp. 89-97).

17- Allahverdiyev, A. M., Abamor, E. S., Bagirova, M., Ustundag, C. B., Kaya, C., Kaya, F., \& Rafailovich, M, "Antileishmanial effect of silver nanoparticles and their enhanced antiparasitic activity under ultraviolet light". International journal of Nanomedicine, 2011, 6, 2705.

18- Baiocco, P., Ilari, A., Ceci, P., Orsini, S., Gramiccia, M., Di Muccio, T., \& Colotti, G., "Inhibitory effect of silver nanoparticles on trypanothione reductase activity and Leishmania infantum proliferation", ACS medicinal chemistry letters, 2011,2(3),230- 233. 